even the oldest of the English maces", and that the Natural Philosophy (anglicé Physics) Department houses the finest extant Elizabethan scientific instrument, Humphrey Cole's great astrolabe (1575). At their best, Scottish professors of chemistry have been men of erudition, and Prof. Read, present director of the Chemical Research Laboratories at St. Andrews, maintains that valuable, if passing, tradition. Not a few who have never heard of terpenes may be inspired by his pamphlet, if they are fortunate enough to see it, to make a post-war pilgrimage to the "little city, worn and grey".

\section{Relation of Meteors to Short-Wave Radio 'Whistles'}

A NOVEL explanation of some peculiar whistles audible under certain conditions in short-wave radio receivers is put forward by $\mathbf{S}$. R. Khastgir (Indian J. Phys., 17, 239; 1943). Weak short-lived whistles of rapidly descending pitch have been noticed at the Delhi receiving station of All-India Radio when a receiver is tuned to the carrier wave of the nearby short-wave transmitters. Two possible explanations are offered, in both of which the phenomenon is attributed to the entrance of a meteor into the earth's upper atmosphere. In the first, the meteor is supposed to produce a rapidly moving mass of ionized air at its head. This local Heaviside layer scatters the incident radiation from the transmitter, the rapid descent causing a Doppler change in the frequency of the scattered waves. These then interfere with the ground waves reaching the receiver, and an audible beat note is produced. As the descent is retarded by atmospheric resistance the Doppler shift lessens, and the pitch of the whistle drops. On a carrier wave of 7 Mc./s. a whistle starting at 3,000 c. $/ \mathrm{s}$. would be caused by a meteor with a maximum velocity component of $64 \mathrm{~km} . / \mathrm{s}$. towards the receiver-not an unreasonable value.

The second hypothesis supposes that the retardation of the meteor in the ionosphere produces, in some way, an electrical impulse similar to audio-frequency static. The Fourier components of this impulse, transmitted at different velocities through the ionosphere, will reach its lower fringe in succession (the shorter waves first) and will modulate the scattered carrier waves at a frequency which is a function of time. A receiver tuned to the carrier will thus reproduce a whistle descending in pitch at a rate which should depend on the ionization. Test experiments will no doubt distinguish between these hypotheses, but there seems no doubt about the observed factsthat the whistles frequently coincide with observed meteors, and that they occur most often in the early morning, when the number of meteors is a maximum. They are thus likely to be of fundamentally meteoric origin whatever may be the details of their production.

\section{Polish Science and Learning}

THE fourth number of Polish Science and Learning, the series of booklets edited by the Association of Polish University Professors and Lecturers in Great Britain, is a specially educational issue. Several preliminary articles are contributed by American and British writers. Dr. Maxwell Garnett's theme is English education in relation to international problems. The makers of the Paris Peace, a quarter of a century ago, he says, took no account of education and little of economics, but relied on political pacts, unsupported by the thoughts and feelings of average citizens. All will agree that we must do better this time, though all may not agree with the details of Dr. Garnett's way of doing it. Prof. Powicke's article, though written for a different occasion, is wisely included, because of its explanation of Oxford's peculiar contribution to English life, the claims of mere learning being subordinated to the service which learning can render to English society. We may be amateurs, but we are not pedants.

The main body of the booklet, contributed by Polish authorities, makes sad reading, because every aspect of education is necessarily treated from the pre-war and the post-war points of view. In other words, the writers describe what has been ruthlessly and completely destroyed, and proceed to describe the immense task of reconstruction which faces the Poland of the future. No aspect of education seems to have been omitted by the editorial committee. Among the subjects of the articles are elementary schools, secondary education, the training of teachers, technical schools, university education, scientific and technical research, books and libraries, adult education, art education and physical education. The concluding "Chronicle" is a useful addition to a very comprehensive report on the educational situation of Poland.

\section{Blind Workers in Industry}

Certain occupations such as basket-making, massage and telephone-exchange operations have been assumed to be almost the only possibilities for the blind, and the normal factory environment has been dismissed as unsuitable. Since the need for labour during the War, many firms have experimented with a few blind workers, and a study of 215 blind workers employed in different firms has been made by Dr. K. G. Fenelon, of the University of Manchester. The industries included, among others, general electrical engineering, aircraft, metal ware, wood-working. 104 of the workers were trained by the firms themselves on the factory premises, 53 by the Institute for the Blind, 2 by an education committee, 8 in their own homes, while 48 had no specific training but obtained their experience on the job. The firms who have experimented with blind workers report that, while some fall short of the production obtained by the fully sighted workers, yet some are quite up to normal standards and also that they are no more liable to accidents than other workers. Some jobs involve the provision of special aids, but others can be undertaken by them with the ordinary machinery. They are particularly successful in work where delicacy of touch compensates for ability to see. It is therefore important that the jobs selected for them should be suited to their particular abilities. Their concentration on the job in hand is good, and they are in general keen and industrious. One difficulty is that they are apt to get irritated by any hold-up of material. It seems clear even from this limited survey that there is a case for a comprehensive research into the possibilities for the blind. Quite apart from their potential value as workers, it will be an advantage to them to form part of an ordinary community.

\section{Rickettsiasis in Brazil}

The January issue of the Boletin de la Oficina Sanitaria Pan-Americana contains an interesting. review of this subject by Dr. Otávio Magalhães, member of the Pan-american Typhus Committee. 